\title{
Optical and Electrical Properties of Magnetron Sputtering Deposited Cu-Al-O Thin Films
}

\author{
Yongjian Zhang, ${ }^{1}$ Zhengtang Liu, ${ }^{1}$ Duyang Zang, ${ }^{2}$ Liping Feng, ${ }^{1}$ \\ Xingsen Che, ${ }^{1}$ and Yanyan $\mathrm{Li}^{1}$ \\ ${ }^{1}$ State Key Laboratory of Solidification Processing School of Materials Science and Engineering, \\ Northwestern Polytechnical University, Xi'an 710072, China \\ ${ }^{2}$ Key Laboratory of Space Applied Physics and Chemistry of Ministry of Education, School of Science, \\ Northwestern Polytechnical University, Xi'an 710129, China \\ Correspondence should be addressed to Zhengtang Liu, liuzht@nwpu.edu.cn \\ Received 27 May 2012; Accepted 9 July 2012 \\ Academic Editor: Fuli Zhang
}

Copyright ( $\odot 2012$ Yongjian Zhang et al. This is an open access article distributed under the Creative Commons Attribution License, which permits unrestricted use, distribution, and reproduction in any medium, provided the original work is properly cited.

We have successfully prepared $\mathrm{Cu}-\mathrm{Al}-\mathrm{O}$ films on silicon (100) and quartz substrates with copper and aluminum composite target by using radio frequency (RF) magnetron sputtering method. We have related the structural and optical-electrical properties of the films to the sputtering area ratio of $\mathrm{Cu} / \mathrm{Al}$ for the target $\left(r_{\mathrm{Cu} / \mathrm{Al}}\right)$. The deposition rate of the film and $r_{\mathrm{Cu} / \mathrm{Al}} \mathrm{can}$ be fitted by an exponential function. $r_{\mathrm{Cu} / \mathrm{Al}}$ plays a critical role in the final phase constitution and the preferred growth orientation of the $\mathrm{CuAlO}{ }_{2}$ phase, thus affecting the film surface morphology significantly. The film with main phase of $\mathrm{CuAlO}_{2}$ has been obtained with $r_{\mathrm{Cu} / \mathrm{Al}}$ of $45 \%$. The films show p-type conductivity. With the increase of $r_{\mathrm{Cu} / \mathrm{Al}}$, the electrical resistivity decreases first and afterwards increases again. With $r_{\mathrm{Cu} / \mathrm{Al}}$ of $45 \%$, the optimum electrical resistivity of $80 \Omega \cdot \mathrm{cm}$ is obtained, with the optical transmittance being $72 \%-79 \%$ in the visible region $(400-760 \mathrm{~nm})$. The corresponding direct band gap and indirect band gap are estimated to be $3.6 \mathrm{eV}$ and $1.7 \mathrm{eV}$, respectively.

\section{Introduction}

Transparent conducting oxide (TCO) films have been widely used in the fields of flat panel displays, solar cells, touch panels, and other optoelectronic devices owing to their high electrical conductivity and optical transmittance in visible region [1-3]. Up to now, however, most of the TCOs obtained are characterized by n-type conductivity. The lack of p-type TCOs restricts the development of $p-n$ junction based device. Therefore, developing stable p-type TCOs becomes the hot research topic $[4,5]$. Kawazoe et al. [6] investigated delafossite-structured $\mathrm{CuAlO}_{2}$ and successfully prepared $\mathrm{CuAlO}_{2}$ films using pulse laser deposition (PLD) method in 1997. The obtained films are good p-type TCO materials, with room temperature electrical conductivity being $0.095 \mathrm{Scm}^{-1}$, optical transmittance being $80 \%$ and direct band gap being $3.5 \mathrm{eV}$. Alternatively, Gao et al. [7] had fabricated p-type transparent $\mathrm{CuAlO}_{2}$ thin films by spinon technique and reported the film had a conductivity of $2.4 \mathrm{Scm}^{-1}$ with the optical band gap being $3.75 \mathrm{eV}$. Due to the excellent optical-electrical properties, $\mathrm{CuAlO}_{2}$ film is attracts increasing research interest for the potential applications ranging from $\mathrm{p}-\mathrm{n}$ junction to invisible circuits.

So far, various deposition techniques have been employed to fabricate highly transparent conductive $\mathrm{CuAlO}_{2}$ thin films, including chemical vapor deposition (CVD) [8], pulsed laser deposition (PLD) [9, 10], sol-gel [11], and sputtering [12, 13]. Among these techniques, RF magnetron sputtering takes the advantage of strong adhesion between film and substrate, large area deposition, low substrate temperature, and good compatibility with current microelectronics. However, various deposition parameters such as oxygen partial pressure, the variety of sputtering target, and sputtering power may influence the 
properties of the films. Furthermore, most of the $\mathrm{CuAlO}_{2}$ films deposited by RF sputtering method are always using high-cost $\mathrm{CuAlO}_{2}$ ceramic target. In this work, we simplify the preparation process by using the low-cost copper and aluminum composite target instead of $\mathrm{CuAlO}_{2}$ ceramic target. We investigate the influence of sputtering area ratio of $\mathrm{Cu} / \mathrm{Al}$ for the target $\left(r_{\mathrm{Cu} / \mathrm{Al}}\right)$ on the properties of obtained films. We elucidate the underlying mechanisms between the film structure and the optical band gap.

\section{Experimental}

$\mathrm{Cu}-\mathrm{Al}-\mathrm{O}$ films were deposited on silicon (100) and quartz substrates, respectively, by RF magnetron sputtering method at room temperature $\left(\sim 22^{\circ} \mathrm{C}\right)$. High purity of $99.999 \%$ copper and aluminum composite target was used as the sputtering materials. The composition of the film was controlled by changing the sputtering area ratio $r_{\mathrm{Cu} / \mathrm{Al}}$ of $\mathrm{Cu}$ and $\mathrm{Al}$ for the target. Pure argon and oxygen were used as sputtering gas and reactive gas, respectively. The substrates were cleaned ultrasonically in 5\% (volume content) HF, acetone and ethanol for silicon, in acetone, and ethanol for quartz before being loaded into the chamber. The HF solution was stored in closed plastic container, and it was used following the safety rules [14, 15], such as wearing special respirator and gloves to prevent the HF from contacting our skin. Before deposition, base pressure of the chamber was evacuated to $4 \times 10^{-4} \mathrm{~Pa}$ by rotary and molecular pump. During deposition process, the working pressure was maintained at $0.3 \mathrm{~Pa}$ and sputtering power was fixed at $80 \mathrm{~W}$. We varied the $r_{\mathrm{Cu} / \mathrm{Al}}$ over the range $20 \%-55 \%$ to ensure the composition changed from Al being excessive to $\mathrm{Cu}$ being excessive. The thickness of the films was controlled being $300 \pm 10 \mathrm{~nm}$ via the deposition duration time. Before characterized the properties, the samples were annealed in GSL-1400X tubular furnace with argon ambience for $3 \mathrm{~h}$.

The thickness of the films was measured by UVISEL ER wide spectral range Ellipse leaning meter. The structural character was identified by using X'Pert Pro MPD X-ray diffractometer with $\mathrm{Cu} \mathrm{K} \alpha(\lambda=0.15406 \mathrm{~nm})$ radiation. The surface morphology and chemical compositions were characterized by ZEISS-SUPRA-55 scanning electron microscope (SEM) and OXFORD INCA PentaFET $\times 3$ energy dispersive spectrometer (EDS). An X-ray photoelectron spectroscopy (XPS) apparatus (PHI-5400) was employed to determine the chemical valence of the elements. The conductivity type was identified by HMS-7077 measurement system. Room temperature resistivity of the films was investigated by the four-probe method in Agilent 4155c measurement system. UV-3150 spectrophotometer was used to measure the optical transmittance of the films.

\section{Results and Discussion}

The deposition rate $R_{D}$ is one of the most important parameters of the deposition process, which plays an important role in the structure and the properties of the films. It can be obtained through dividing the thickness by deposition time.
Figure 1 illustrates the effect of $r_{\mathrm{Cu} / \mathrm{Al}}$ on the deposition rate $R_{D}$ of the $\mathrm{Cu}-\mathrm{Al}-\mathrm{O}$ films on $\mathrm{Si}(100)$ substrate. $R_{D}$ increases from $1.13 \mathrm{~nm} \cdot \mathrm{min}^{-1}$ to $1.46 \mathrm{~nm} \cdot \mathrm{min}^{-1}$ with the increase of $r_{\mathrm{Cu} / \mathrm{Al}}$ from $20 \%$ to $55 \%$. The results can be fitted by an exponential function as

$$
R_{D}=1.5-2.3 \exp \left(-0.1 \cdot r_{\mathrm{Cu} / \mathrm{Al}}\right)
$$

The deposition rate $R_{D}$ increases with the increase of $r_{\mathrm{Cu} / \mathrm{Al}}$ is mainly due to that the sputtering yield of $\mathrm{Cu}$ is higher than that of $\mathrm{Al}$. In addition, the sputtered $\mathrm{Cu}$ atom possesses more energy than $\mathrm{Al}$, thus favoring the formation of defect and nucleation center on the substrate. This also contributes to the increase of $R_{D}$.

Figure 2 plots the X-ray diffraction spectra of $\mathrm{Cu}-\mathrm{Al}-$ O films deposited with different $r_{\mathrm{Cu} / \mathrm{Al}}$. When $r_{\mathrm{Cu} / \mathrm{Al}}$ is $20 \%$, the diffraction peaks corresponding to $\mathrm{CuAlO}_{2}$ (104), (015), (009), (116) and $\mathrm{Al}_{2} \mathrm{O}_{3}$ (113), (306) are observed, indicating an excess of $\mathrm{Al}$ element exists in the film. When $r_{\mathrm{Cu} / \mathrm{Al}}$ increases to $45 \%$, the $\mathrm{CuAlO}_{2}$ (018) peak grows remarkably while $\mathrm{Al}_{2} \mathrm{O}_{3}$ peaks tend to reduce. $\mathrm{CuAlO}_{2}$ becomes the main phase of the film. The change may be due to the following reaction [16]:

$$
\mathrm{Al}_{2} \mathrm{O}_{3}+\mathrm{Cu}_{2} \mathrm{O} \rightarrow \mathrm{CuAlO}_{2}
$$

When the $r_{\mathrm{Cu} / \mathrm{Al}}$ reaches $55 \%$, a new peak at $36.4^{\circ}$ which is identified to $\mathrm{Cu}_{2} \mathrm{O}$ (111) emerges, suggesting the surplus of $\mathrm{Cu}$ element in the film.

The $r_{\mathrm{Cu} / \mathrm{Al}}$ also plays an important role in the preferred growth orientation of $\mathrm{CuAlO}_{2}$ diffraction peaks. As seen from Figure 2, with $r_{\mathrm{Cu} / \mathrm{Al}}$ of $20 \%, \mathrm{CuAlO}_{2}$ phase shows strong peak along (104) and (015) crystal planes, while the $\mathrm{X}$-ray diffraction peak of $(018)$ is weak. With $r_{\mathrm{Cu} / \mathrm{Al}}$ increases to $45 \%$, the peak of $\mathrm{CuAlO}_{2}(018)$ increases significantly and becomes the strongest, suggesting that the preferred growth orientation of $\mathrm{CuAlO}_{2}$ is $(018)$ with this $r_{\mathrm{Cu} / \mathrm{Al}}$. When the $r_{\mathrm{Cu} / \mathrm{Al}}$ is $55 \%$, (018) peak of $\mathrm{CuAlO}_{2}$ weakens and the preferential growth changes into (104). Although the surface energy of (001) crystal plane might be the lowest in delfossite structure $\mathrm{CuAlO}_{2}$ crystal, the kinetic parameters, for instance, annealing treatment, may also play a role in the selection of the preferred growth orientation.

The grain size can be estimated from the full-width halfmaximum intensity of XRD peak by using Scherrer's relation [17]:

$$
d=\frac{k \lambda}{\beta \cos \theta},
$$

where $k$ is a constant of 0.89 for $\mathrm{Cu}$ target, $\lambda=0.15406 \mathrm{~nm}$, $\theta$ and $\beta$ are the Bragg diffraction angle and half intensity width. The calculated grain sizes of the films are estimated to be $12.6 \mathrm{~nm}, 14.1 \mathrm{~nm}, 17.4 \mathrm{~nm}$, and $15.2 \mathrm{~nm}$ for $r_{\mathrm{Cu} / \mathrm{Al}}$ of $20 \%, 30 \%, 45 \%$, and $55 \%$, respectively.

Figure 3 displays the typical SEM images and the corresponding EDS spectra of the films deposited with different $r_{\mathrm{Cu} / \mathrm{Al}}$ on Si (100) substrate. With $r_{\mathrm{Cu} / \mathrm{Al}}$ being $20 \%$, a large amount of globular precipitation phases have been observed, as shown in Figure 3(a). Figure 3(b) illustrates the 


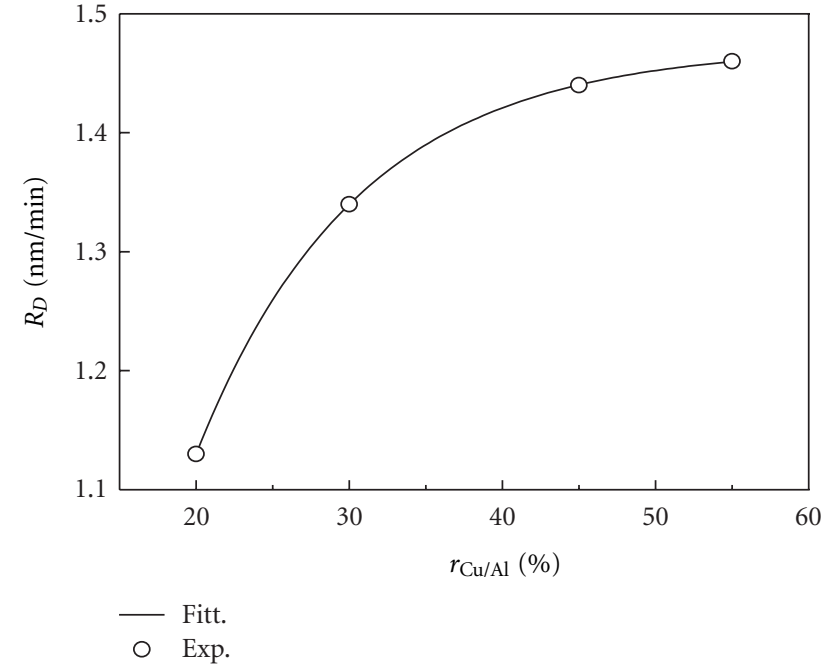

FIgURE 1: Deposition rate $R_{\mathrm{D}}$ of the films as a function of sputtering area ratio of $\mathrm{Cu} / \mathrm{Al}$ for sputtering target $\left(r_{\mathrm{Cu} / \mathrm{Al}}\right)$.

EDS spectrum of the globular phases, showing the atomic ratio of $\mathrm{Al}: \mathrm{O}$ is around $2: 3$. This suggests that the globular phase is $\mathrm{Al}_{2} \mathrm{O}_{3}$. Figure 3(c) demonstrates the image of the film deposited with $r_{\mathrm{Cu} / \mathrm{Al}}$ being $45 \%$. The film shows a uniform microstructure with well-defined grain boundaries, no impurity is observed. EDS spectrum of the film signifies the atomic ratio of $\mathrm{Cu}: \mathrm{Al}: \mathrm{O}$ is about $1: 1: 2$, confirming the XRD analysis that $\mathrm{CuAlO}_{2}$ is the main phase of the film. When the $r_{\mathrm{Cu} / \mathrm{Al}}$ increases to $55 \%$, a nonfaceted phase is observed. EDS analysis of this phase shows that the atomic ratio of $\mathrm{Cu}: \mathrm{Al}: \mathrm{O}$ is about $12: 1: 5$, indicating the precipitation phase is mainly composed of copper oxide, which is consistent with the XRD result.

To further identify the chemical compositions and valences of the elements, we performed XPS analysis to the films deposited on $\mathrm{Si}$ (100) substrate. Figures 4(a)-4(c) show the typical XPS spectra of the $\mathrm{Cu}-\mathrm{Al}-\mathrm{O}$ film obtained with $r_{\mathrm{Cu} / \mathrm{Al}}=45 \%$ after the calibration using $\mathrm{C} 1 \mathrm{~s}$ position of carbon. As shown in Figure 4(a), the "shake-up" peak of the $\mathrm{Cu}^{2+} 2 \mathrm{p}_{3 / 2}$ at around $943 \mathrm{eV}$ is not observed, indicating that no $\mathrm{Cu}^{2+}$ presents in the film. Figure 4(b) shows the $\mathrm{Cu} 2 \mathrm{p}_{3 / 2}$ peak together with the two separated peaks by using the multipeaks fitting. The peak at the low binding energy of $931.7 \mathrm{eV}$ is corresponding to $\mathrm{Cu}^{+}$in $\mathrm{CuAlO}_{2}$, while the high binding energy $932.8 \mathrm{eV}$ is corresponding to $\mathrm{Cu}_{2} \mathrm{O}$. The intensity of the low-energy peak $(931.7 \mathrm{eV})$ is remarkably higher than that of the high-energy peak $(932.8 \mathrm{eV})$, suggesting $\mathrm{Cu}^{+}$mainly exists in $\mathrm{CuAlO}_{2}$ phase. The $\mathrm{Al} 2 \mathrm{p}$ peak region, shown in Figure 4(c), consists of $\mathrm{Al}$ $2 \mathrm{p}$ peak of $\mathrm{Al}^{3+}$ (around 74.2 $\mathrm{eV}$ ), $\mathrm{Cu} 3 \mathrm{p}_{3 / 2}$ (around $75.3 \mathrm{eV}$ ), and $\mathrm{Cu} 3 \mathrm{p}_{1 / 2}(77.1 \mathrm{eV})$ peaks of $\mathrm{Cu}^{+}$, which is similar to the result reported by Cai et al. [16].

The $\mathrm{Cu} 2 \mathrm{p}$ spectra of the other films are similar to that shown in Figure 4(a) where no $\mathrm{Cu}^{2+}$ peaks have been observed. This is consistent with the XRD results: no $\mathrm{CuO}$ or $\mathrm{CuAl}_{2} \mathrm{O}_{4}$ diffraction peak is observed in the XRD patterns.

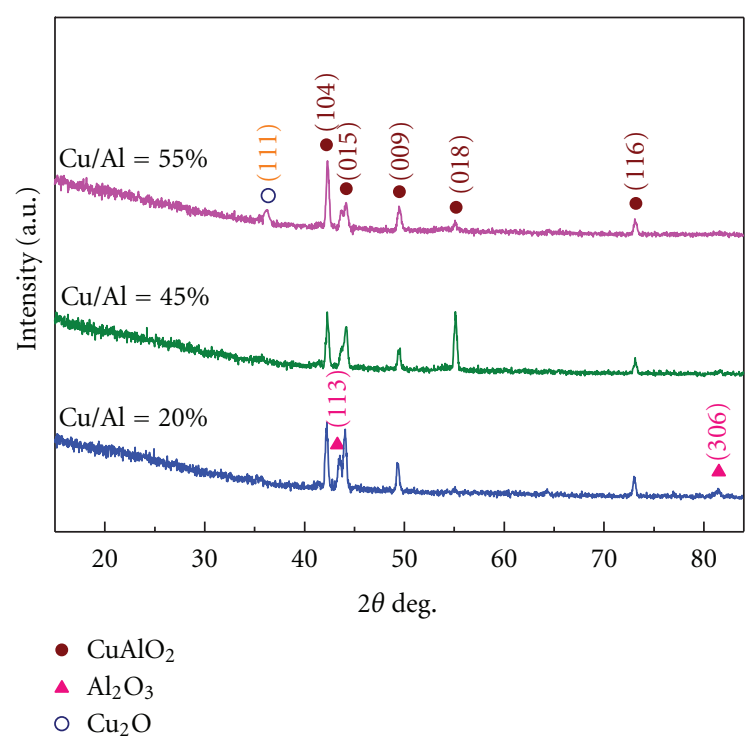

FIGURE 2: XRD patterns of $\mathrm{Cu}-\mathrm{Al}-\mathrm{O}$ thin films deposited with different $r_{\mathrm{Cu} / \mathrm{Al}}$ on $\mathrm{Si}(100)$ substrate.

The conductivity type of the films deposited on quartz substrate was measured by Hall effect measurement and the electrical resistivity $(\rho)$ at room temperature was studied by four-probe method. Prior to the investigation, four $\mathrm{Au}$ electrodes were deposited on the film surface.

Figure 5 shows the electrical resistivity $(\rho)$ of the films formed with different $r_{\mathrm{Cu} / \mathrm{Al}}$ and the inset demonstrates the relation between current and voltage for the film deposited with $r_{\mathrm{Cu} / \mathrm{Al}}$ of $45 \%$. From the inset $I-V$ curve, it can be seen the linear dependence is obtained, which indicates ohmic contact has been achieved between Au electrode and the film. With $r_{\mathrm{Cu} / \mathrm{Al}}$ being $20 \%$, the sample shows a high electrical resistivity due to the existence of large amount of insulating $\mathrm{Al}_{2} \mathrm{O}_{3}$ in the film [18]. When $r_{\mathrm{Cu} / \mathrm{Al}}$ increases from $20 \%$ to $45 \%$, the electrical resistivity $(\rho)$ decreases from $243 \Omega \cdot \mathrm{cm}$ to $80 \Omega \cdot \mathrm{cm}$. The reason may be that the improvement of crystallization quality reduces the scattering and trapping of charge carriers, leading to the enhancement of Hall mobility. Furthermore, the increment of $\mathrm{CuAlO}_{2}$ increases the carrier concentration of the film. With $r_{\mathrm{Cu} / \mathrm{Al}}$ being $55 \%$, the electrical resistivity $(\rho)$ increases to $156 \Omega \cdot \mathrm{cm}$. In this case, surplus copper element exists in the film and the copper vacancy which can produce hole carrier concentration decreases. In addition, the emergence of $\mathrm{Cu}_{2} \mathrm{O}$ impurity strengthens the scattering and trapping of charge carriers, decreasing the Hall mobility.

Figure 6 presents the optical transmittance spectra of the $\mathrm{Cu}-\mathrm{Al}-\mathrm{O}$ thin films deposited with different $r_{\mathrm{Cu} / \mathrm{Al}}$ on quartz substrate. As can be seen, the film deposited with $r_{\mathrm{Cu} / \mathrm{Al}}$ of $20 \%$ exhibits the highest transmittance $(77 \%-84 \%)$ in the visible region $(400-760 \mathrm{~nm})$. It may be due to the large amount of $\mathrm{Al}_{2} \mathrm{O}_{3}$ precipitation phase, which has quite high transmittance in the visible range, existing in the film. With $r_{\mathrm{Cu} / \mathrm{Al}}$ being $30 \%$, a decrease $(58 \%-76 \%)$ in the film transmittance was observed. When $r_{\mathrm{Cu} / \mathrm{Al}}$ increases to $45 \%$, 


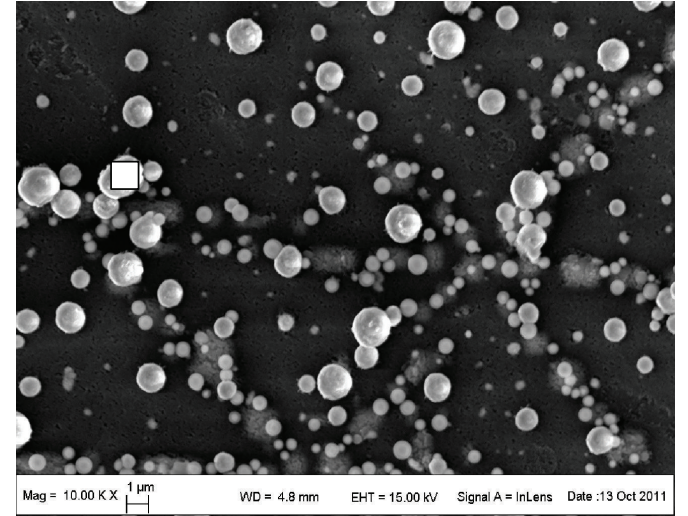

(a)

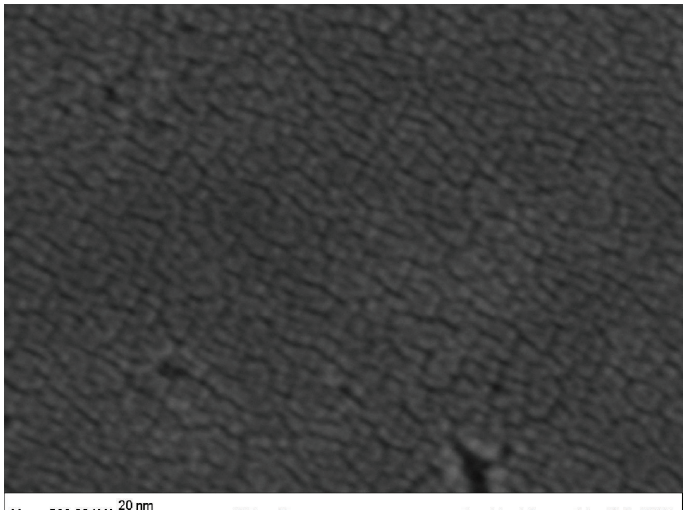

Mag $=500.00 \mathrm{Kx}$ $W D=4.5 \mathrm{~mm} \quad E H T=15.00 \mathrm{kV} \quad$ Signal $A=\mid$ InLens Date $: 13$ Oct 2011

(c)

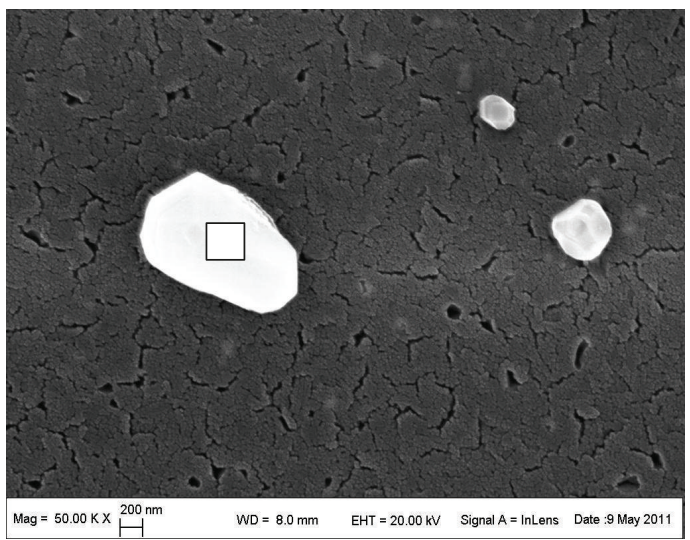

(e)

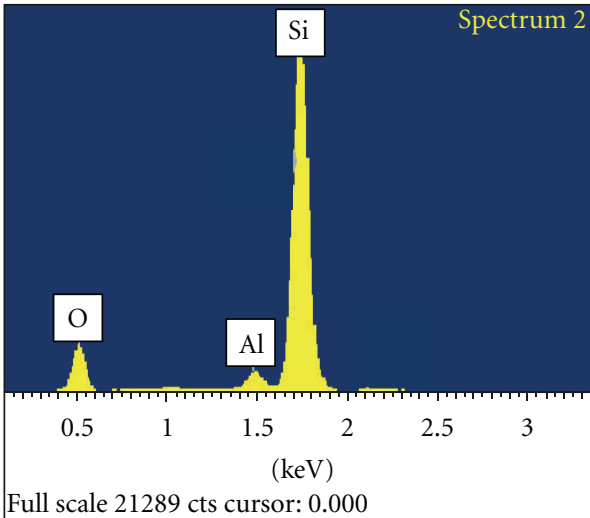

(b)

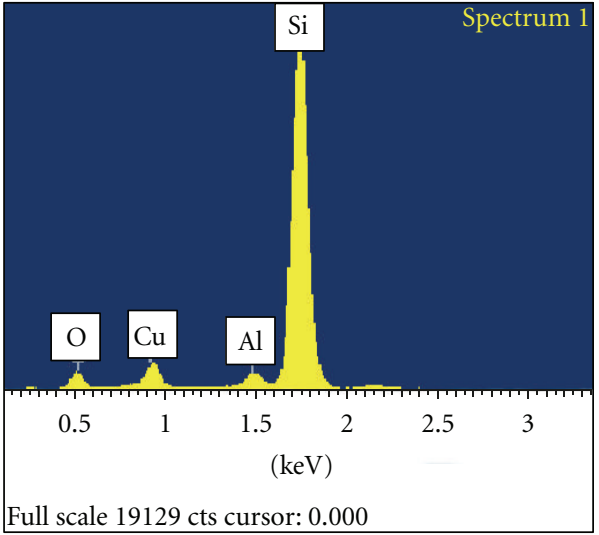

(d)

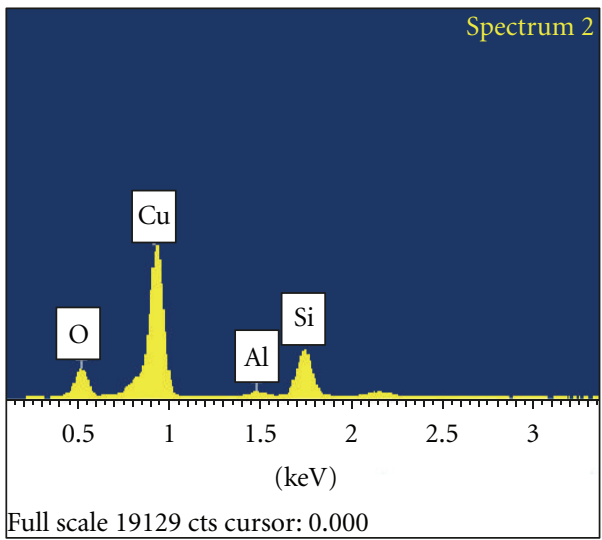

(f)

Figure 3: SEM micrographs and EDS spectra of Cu-Al-O thin films obtained with different $r_{\mathrm{Cu} / \mathrm{Al}}$ : (a) and (b) $r_{\mathrm{Cu} / \mathrm{Al}}=20 \%$; (c) and (d) $r_{\mathrm{Cu} / \mathrm{Al}}=45 \%$; (e) and (f) $r_{\mathrm{Cu} / \mathrm{Al}}=55 \%$.

the transmittance of the film increases to $72 \%-79 \%$ in the visible region (400-760 nm) due to that the $\mathrm{CuAlO}_{2}$ becomes the predominant phase. In addition, the decrease of defect density and crystallization improvement of the films also contribute to the improvement of optical transmittance. When $r_{\mathrm{Cu} / \mathrm{Al}}$ reaches $55 \%$, the transmittance decreases again, mainly because the coexistence of $\mathrm{Cu}_{2} \mathrm{O}$ phase strengthen the scattering effect, lowering the optical transmittance [18].
To further investigate the optical properties, we evaluated the optical band gap $\left(E_{g}\right)$ of the $\mathrm{Cu}-\mathrm{Al}-\mathrm{O}$ thin films. The optical absorption coefficient $(\alpha)$ of the films can be calculated using the following equation:

$$
\alpha=\frac{1}{d} \ln \left(\frac{1}{T}\right)
$$




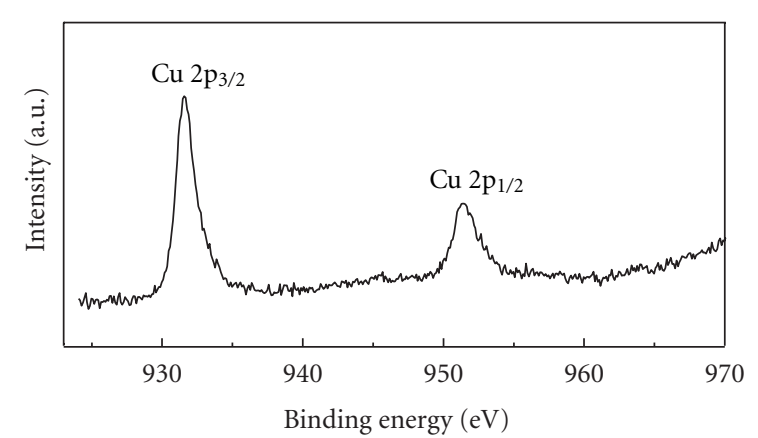

(a)

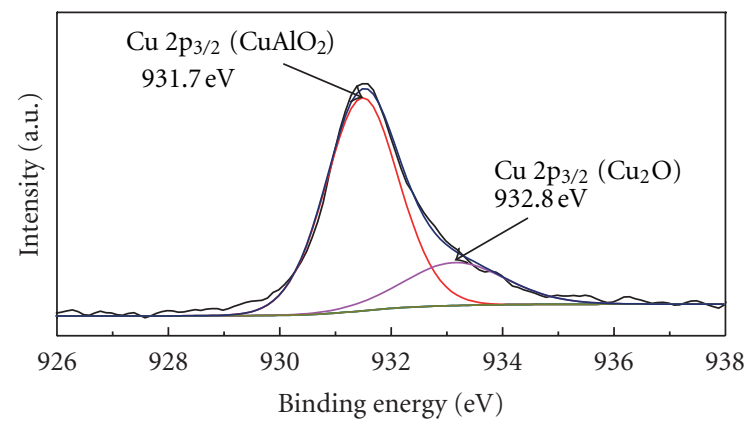

(b)

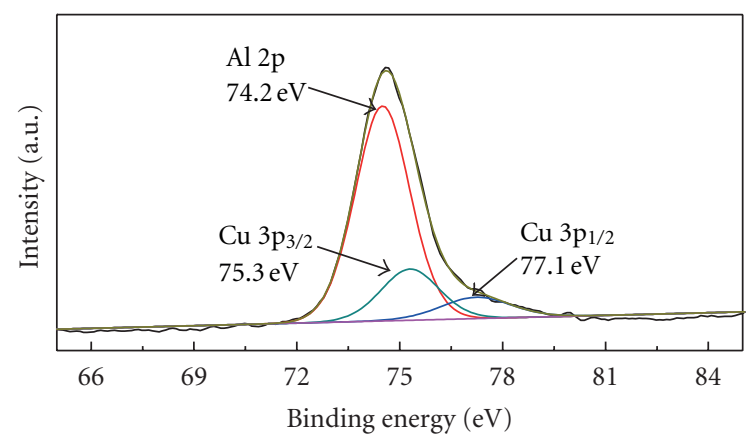

(c)

FIgURE 4: XPS spectra of Cu-Al-O thin films obtained with $r_{\mathrm{Cu} / \mathrm{Al}}$ of $45 \%$ : (a) $\mathrm{Cu} 2 \mathrm{p}$ spectra; (b) fitting spectra of $\mathrm{Cu} 2 \mathrm{p}_{3 / 2}$; (c) fitting spectra of $\mathrm{Al} 2 \mathrm{p}$ and $\mathrm{Cu} 3 \mathrm{p}$.

where $d$ is the film thickness and $T$ is the transmittance of the film. The relation between optical absorption coefficient $(\alpha)$ and optical band gap $\left(E_{g}\right)$ can be written as

$$
(\alpha h v)^{1 / n}=A\left(h v-E_{g}\right),
$$

where $A$ is the absorption edge width parameter and $h v$ means the incident photon energy. The exponential $n$ is $1 / 2$ or 2 for direct allowed transition $\left(E_{\mathrm{gd}}\right)$ or indirect allowed transition $\left(E_{\mathrm{gi}}\right)$.

Figure 7 shows a typical linear fitting process of $E_{g}$ for the $\mathrm{Cu}-\mathrm{Al}-\mathrm{O}$ thin film deposited at $r_{\mathrm{Cu} / \mathrm{Al}}=45 \% . E_{\mathrm{gd}}$ and $E_{\text {gi }}$ are obtained from the intercept on $h v$ axis in the plots of $(\alpha h \nu)^{2}-h v$ and $(\alpha h \nu)^{1 / 2}-h v$, respectively. Figure 8 compares the $E_{\mathrm{gd}}$ and $E_{\mathrm{gi}}$ values of the films deposited with different $r_{\mathrm{Cu} / \mathrm{Al}}$. The $E_{\mathrm{gd}}$ decreases from $5.3 \mathrm{eV}$ to $3.6 \mathrm{eV}$ with increase of $r_{\mathrm{Cu} / \mathrm{Al}}$ from $20 \%$ to $45 \%$, afterwards, it increases to $4.7 \mathrm{eV}$

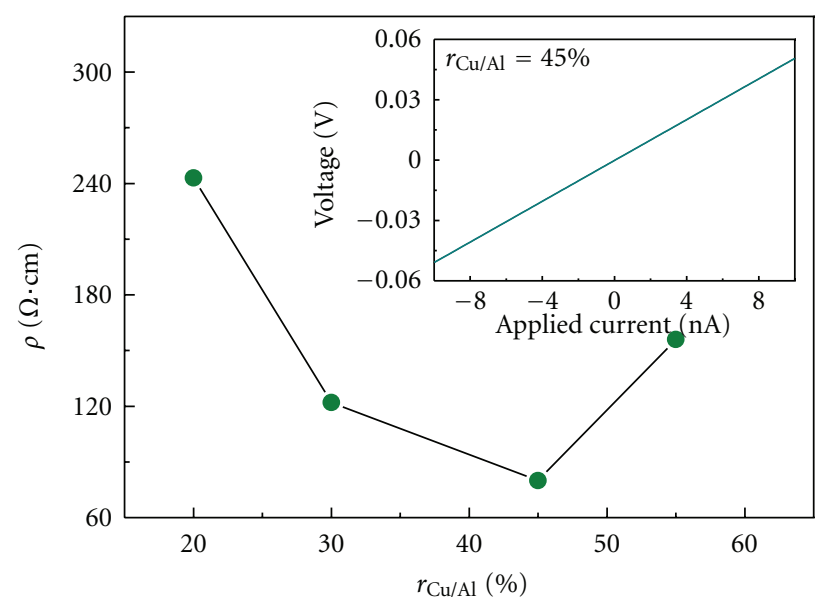

FIGURE 5: Variation of electrical resistivity with different $r_{\mathrm{Cu} / \mathrm{Al} \text {. Inset }}$ shows the $I-V$ relation for the sample deposited with $r_{\mathrm{Cu} / \mathrm{Al}}$ of $45 \%$.

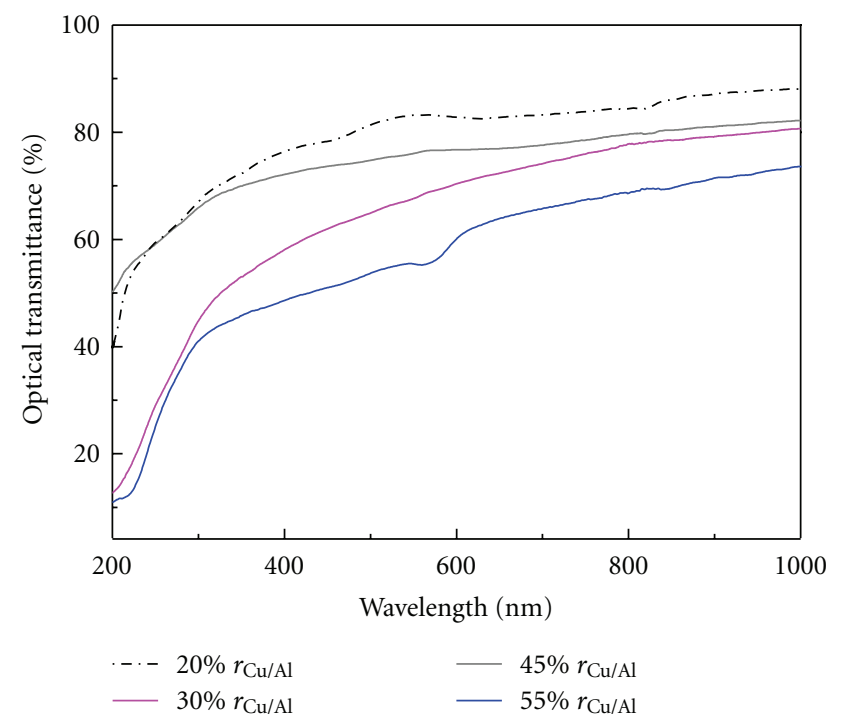

Figure 6: Optical transmittance spectra of $\mathrm{Cu}-\mathrm{Al}-\mathrm{O}$ films deposited with different $r_{\mathrm{Cu} / \mathrm{Al}}$.

with $r_{\mathrm{Cu} / \mathrm{Al}}$ reaching $55 \%$. $E_{\mathrm{gi}}$ varies in the range of $1.6-1.9 \mathrm{eV}$ and achieves the minimum with $r_{\mathrm{Cu} / \mathrm{Al}}$ of $45 \%$.

$E_{\mathrm{gd}}$ and $E_{\mathrm{gi}}$ may be influenced by the phase constitution of the films. With $r_{\mathrm{Cu} / \mathrm{Al}}$ of $20 \%$, the film is composed of $\mathrm{Al}_{2} \mathrm{O}_{3}$ and $\mathrm{CuAlO}_{2}$ phases, hence, the optical band gap of the film can be evaluated by the superposition of pure $\mathrm{Al}_{2} \mathrm{O}_{3}$ and $\mathrm{CuAlO}_{2}$, whose $E_{\mathrm{gd}}$ are $9.0 \mathrm{eV}$ [19] and $3.5 \mathrm{eV}[6,20]$, respectively. The direct band gap of the film which consists of $\mathrm{Al}_{2} \mathrm{O}_{3}$ and $\mathrm{CuAlO}_{2}$ is assumed to be in the range of 3.5$9.0 \mathrm{eV}$. This is in agreement with our result $5.3 \mathrm{eV}$. For the film deposited with $r_{\mathrm{Cu} / \mathrm{Al}}$ of $45 \%$, the main crystal phase of the film is $\mathrm{CuAlO}_{2}$ and the estimated $E_{\mathrm{gd}}(3.6 \mathrm{eV})$ is close to the $E_{\mathrm{gd}}$ of pure $\mathrm{CuAlO}_{2}(3.5 \mathrm{eV})[6,20]$. 


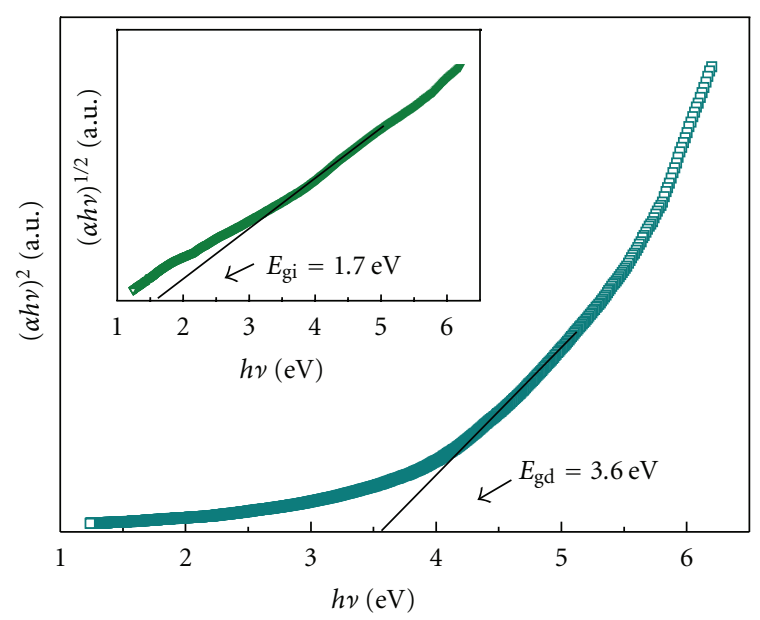

Figure 7: Plots of $(\alpha h \nu)^{2}$ versus $h v$ for the determination of direct band gap $\left(E_{\mathrm{gd}}\right)$ for the film deposited with $r_{\mathrm{Cu} / \mathrm{Al}}$ of $45 \%$ (inset: determination of indirect band gap $\left.E_{\mathrm{gi}}\right)$.

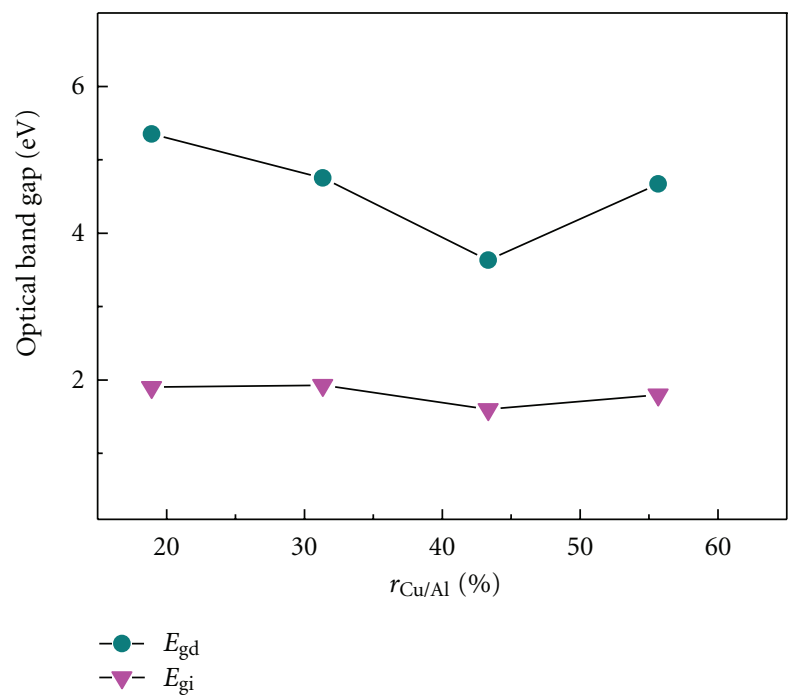

FIGURE 8: Effect of $r_{\mathrm{Cu} / \mathrm{Al}}$ on the optical band gap of the film: (a) direct band gap $E_{\mathrm{gd}}$; (b) indirect band gap $E_{\mathrm{gi}}$.

Moreover, quantum size effect may also affect the band gap, which can be described by the following equation [20]:

$$
E_{g}=\frac{\pi^{2} \hbar^{2}}{2 R^{2}}\left[\frac{1}{m_{e}}+\frac{1}{m_{h}}\right]-\frac{1.8 e^{2}}{\varepsilon_{2} R}+\frac{e^{2}}{R} \sum_{n=1}^{\infty} \alpha_{n}\left(\frac{S}{R}\right)^{2 n},
$$

$R$ is the radius of the semiconductor particle and the first term is the quantum energy of localization for both electron and hole. The second term is the Coulomb attraction and the third term represents the band gap of the bulk semiconductor. As is shown in the model, the change tendency of $E_{g}$ and $R$ is reverse, that is, $E_{g}$ should be smaller for larger $R$. The estimated results show that with the largest grain size $17.4 \mathrm{~nm}\left(r_{\mathrm{Cu} / \mathrm{Al}}=45 \%\right)$, the $E_{\text {gd }}$ achieves the minimum value $3.6 \mathrm{eV}$, while with the minimum grain size $12.6 \mathrm{~nm}\left(r_{\mathrm{Cu} / \mathrm{Al}}=20 \%\right)$, the $E_{\mathrm{gd}}$ obtains the maximum value
$5.3 \mathrm{eV}$, indicating our results is consistent with the model. This suggests that quantum size effect resulted from the nano size grain structure may play a role in the optical band gap of the film.

\section{Conclusions}

$\mathrm{Cu}-\mathrm{Al}-\mathrm{O}$ thin films have been deposited on $\mathrm{Si}(100)$ and quartz substrates by RF magnetron sputtering technique. The sputtering area ratio of $\mathrm{Cu} / \mathrm{Al}$ for the sputtering target $\left(r_{\mathrm{Cu} / \mathrm{Al}}\right)$ plays an important role in the structure, opticalelectrical properties and optical band gaps of the films. The deposition rate $R_{\mathrm{D}}$ increases with the increase of $r_{\mathrm{Cu} / \mathrm{Al}}$ mainly because of the higher sputtering yield of $\mathrm{Cu}$ than Al. With $r_{\mathrm{Cu} / \mathrm{Al}}$ of $20 \%, \mathrm{CuAlO}_{2}$ and $\mathrm{Al}_{2} \mathrm{O}_{3}$ phases coexist in the film due to the surplus $\mathrm{Al}$ element. $\mathrm{CuAlO}_{2}$ becomes the main phase of the film when $r_{\mathrm{Cu} / \mathrm{Al}}$ reaches $45 \%$. Whereas when $r_{\mathrm{Cu} / \mathrm{Al}}$ increases to $55 \%$, as well as the $\mathrm{CuAlO}_{2}, \mathrm{Cu}_{2} \mathrm{O}$ diffraction peak also be detected. $\mathrm{Cu}^{+}$in the films deposited with different $r_{\mathrm{Cu} / \mathrm{Al}}$ exists in the form of $\mathrm{CuAlO}_{2}$ or $\mathrm{Cu}_{2} \mathrm{O}$, no $\mathrm{Cu}^{2+}$ has been observed. The films show stable p-type conductivity. With the increase of $r_{\mathrm{Cu} / \mathrm{Al}}$, the electrical resistivity first decreases afterwards increases. With $r_{\mathrm{Cu} / \mathrm{Al}}$ of $45 \%$, the film shows the optimum opticalelectrical properties. The electrical resistivity is measured to be $80 \Omega \cdot \mathrm{cm}$ with the transmittance being $72 \%-79 \%$ in the visible region $(400-760 \mathrm{~nm})$. The estimated $E_{\mathrm{gd}}$ is in the range of 3.6-5.3 eV and $E_{\mathrm{gi}}$ in the range of $1.6-1.9 \mathrm{eV}$ which depends on $r_{\mathrm{Cu} / \mathrm{Al}}$.

\section{Acknowledgments}

This work was supported by the Shaanxi Provincial Natural Science Foundation of China (Grant no. 2012JQ1016), the Research Fund of the State Key Laboratory of Solidification Processing (Contract nos. 58-TZ-2011 and SKLSP 201217) and the Northwestern Polytechnical University (NPU) Foundation for Fundamental Research (Contract nos. JC20100242 and JC20110245). The authors are grateful to Dr. Y. P. Li and Mr. H. Yuan, for their help with the experiments and analysis.

\section{References}

[1] M. H. Ahn, E.-S. Cho, and S. J. Kwon, "Effect of the duty ratio on the indium tin oxide (ITO) film deposited by in-line pulsed DC magnetron sputtering method for resistive touch panel," Applied Surface Science, vol. 258, no. 3, pp. 1242-1248, 2011.

[2] M. F. Chen, K. M. Lin, and Y. S. Ho, "Effects of laser-induced recovery process on conductive property of $\mathrm{SnO}_{2}: \mathrm{F}$ thin films," Materials Science and Engineering B, vol. 176, no. 2, pp. 127-131, 2011.

[3] K. Tonooka, K. Shimokawa, and O. Nishimura, "Properties of copper-aluminum oxide films prepared by solution methods," Thin Solid Films, vol. 411, no. 1, pp. 129-133, 2002.

[4] K. Nomura, H. Ohta, K. Ueda, T. Kamiya, M. Hirano, and H. Hosono, "Thin-film transistor fabricated in single-crystalline transparent oxide semiconductor," Science, vol. 300, no. 5623, pp. 1269-1272, 2003. 
[5] G. Thomas, "Invisible circuits," Nature, vol. 389, no. 6654, pp. 907-908, 1997.

[6] H. Kawazoe, M. Yasukawa, H. Hyodo, M. Kurita, H. Yanagi, and H. Hosono, "P-type electrical conduction in transparent thin films of $\mathrm{CuAlO}_{2}$," Nature, vol. 389, no. 6654, pp. 939-942, 1997.

[7] S. M. Gao, Y. Zhao, P. Gou, N. Chen, and Y. Xie, "Preparation of $\mathrm{CuAlO}_{2}$ nanocrystalline transparent thin films with high conductivity," Nanotechnology, vol. 14, no. 5, pp. 538-541, 2003.

[8] H. Gong, Y. Wang, and Y. Luo, "Nanocrystalline p-type transparent $\mathrm{Cu}-\mathrm{Al}-\mathrm{O}$ semiconductor prepared by chemical-vapor deposition with $\mathrm{Cu}(\mathrm{acac})_{2}$ and $\mathrm{Al}(\mathrm{acac})_{3}$ precursors," Applied Physics Letters, vol. 76, no. 26, pp. 3959-3961, 2000.

[9] M. Neumann-Spallart, S. P. Pai, and R. Pinto, "PLD growth of $\mathrm{CuAlO}_{2}$," Thin Solid Films, vol. 515, no. 24, pp. 8641-8644, 2007.

[10] J. C. Lee, S. Y. Um, Y. W. Heo, J. H. Lee, and J. J. Kim, "Phase development and crystallization of $\mathrm{CuAlO}_{2}$ thin films prepared by pulsed laser deposition," Journal of the European Ceramic Society, vol. 30, no. 2, pp. 509-512, 2010.

[11] S. Götzendörfer, C. Polenzky, S. Ulrich, and P. Löbmann, "Preparation of $\mathrm{CuAlO}_{2}$ and $\mathrm{CuCrO}_{2}$ thin films by sol-gel processing," Thin Solid Films, vol. 518, no. 4, pp. 1153-1156, 2009.

[12] W. Lan, M. Zhang, G. Dong, P. Dong, Y. Wang, and H. Yan, "The effect of oxygen on the properties of transparent conducting $\mathrm{Cu}-\mathrm{Al}-\mathrm{O}$ thin films deposited by rf magnetron sputtering," Materials Science and Engineering B, vol. 139, no. 2-3, pp. 155-159, 2007.

[13] H. Y. Chen and M. W. Tsai, "Delafossite-CuAlO ${ }_{2}$ films prepared by annealing of amorphous $\mathrm{Cu}-\mathrm{Al}-\mathrm{O}$ films at high temperature under controlled atmosphere," Thin Solid Films, vol. 519, no. 18, pp. 5966-5970, 2011.

[14] D. Peters and R. Miethchen, "Symptoms and treatment of hydrogen fluoride injuries," Journal of Fluorine Chemistry, vol. 79, no. 2, pp. 161-165, 1996.

[15] E. B. Segal, "First aid for a unique acid, HF: a sequel," Chemical Health and Safety, vol. 7, no. 1, pp. 18-23, 2000.

[16] J. Cai and H. Gong, "The influence of $\mathrm{Cu} / \mathrm{Al}$ ratio on properties of chemical-vapor-deposition-grown p-type $\mathrm{Cu}-$ Al-O transparent semiconducting films," Journal of Applied Physics, vol. 98, no. 3, Article ID 033707, 5 pages, 2005.

[17] B. D. Cullity, Elements of X-Ray Diffraction, Addison Wesley, London, UK, 2nd edition, 1978.

[18] A. S. Reddy, P. S. Reddy, S. Uthanna, and G. M. Rao, "Characterization of $\mathrm{CuAlO}_{2}$ films prepared by dc reactive magnetron sputtering," Journal of Materials Science, vol. 17, no. 8, pp. 615-620, 2006.

[19] M. Henyk, D. Wolfframm, and J. Reif, "Ultra short laser pulse induced charged particle emission from wide bandgap crystals," Applied Surface Science, vol. 168, no. 1-4, pp. 263266, 2000.

[20] L. E. Brus, "Electron-electron and electron-hole interactions in small semiconductor crystallites: the size dependence of the lowest excited electronic state," The Journal of Chemical Physics, vol. 80, no. 9, pp. 4403-4409, 1984. 

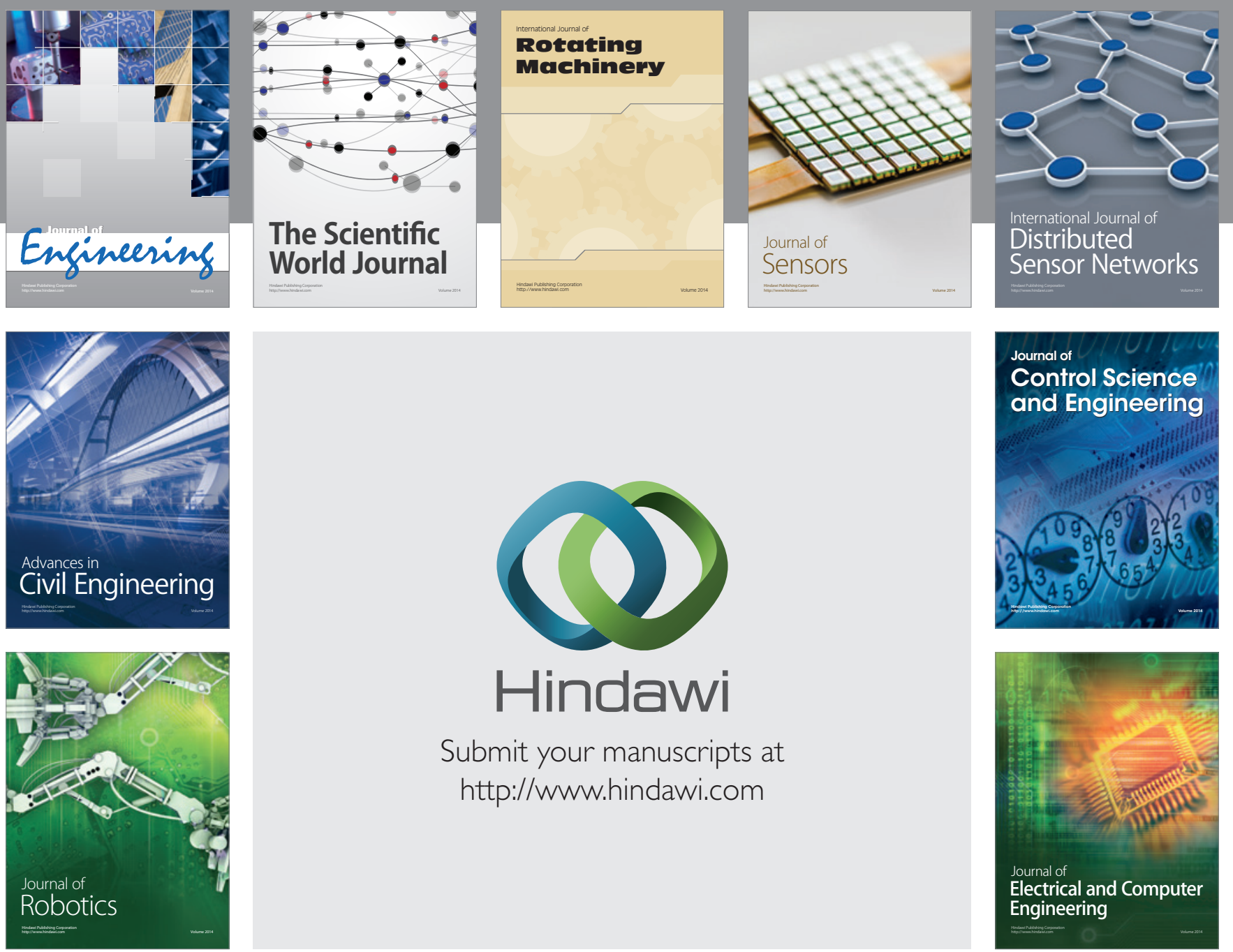

Submit your manuscripts at

http://www.hindawi.com
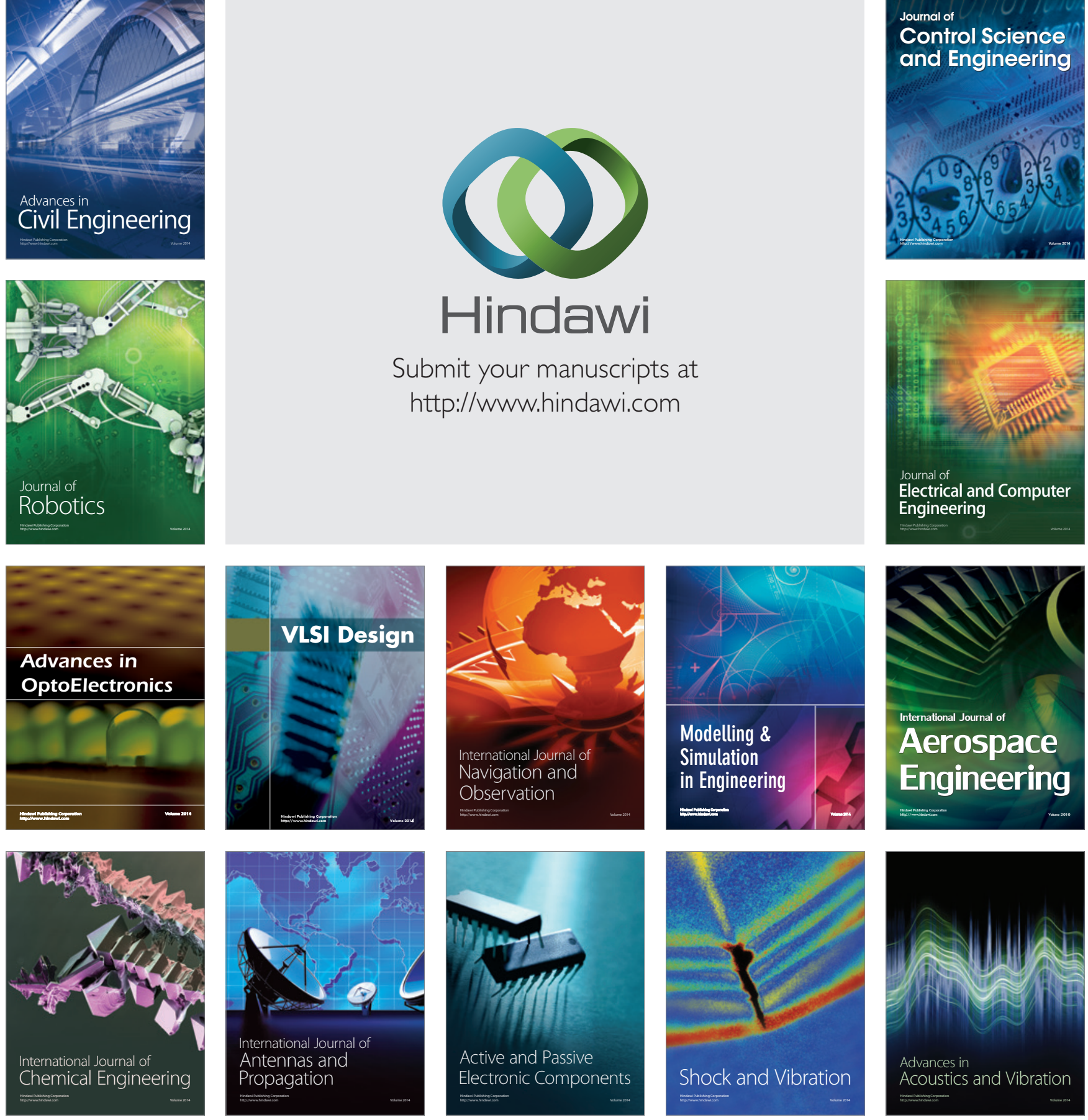